\title{
Making Money from Exploiting Schumpeterian Opportunities: John Sanguinetti and the Electronic Design Automation Industry
}

\author{
Arthur Low
}

\author{
" I was reading EE Times one day in September of 1990," \\ and saw a 2-paragraph article that said ...that Verilog \\ might be made public.... Within 5 seconds of reading that \\ article, I knew that this was the opportunity I'd been \\ looking for. \\ John Sanguinetti \\ Entrepreneur and computer scientist
}

\begin{abstract}
Accounts of the effect that John Sanguinetti's two companies had on the market for integrated circuit design languages were used to gain insights on how to profit from the exploitation of Schumpeterian opportunities. This article will be of interest to entrepreneurs who expect to profit from exploiting opportunities that disrupt the status quo. To write this article, the author reviewed the literature on Schumpeterian and Kirznerian opportunities and examined the writings of and about Sanguinetti and his companies, blogs written by industry insiders, and articles in industry trade journals. Sanguinetti's first company introduced a new technology and his second company introduced a new business strategy and a new technology. Both of Sanguinetti's companies undermined the capital investments of the established incumbents and created new value for customers. The article provides three main insights. First, deep knowledge and experience in the customer domain enable an entrepreneur to recognize and act to profit from a Schumpeterian opportunity. Second, to profit from a Schumpeterian opportunity the entrepreneur needs to combine technology and business model components in a way that adds significant value to customers. Third, large amounts of venture capital may or may not be required to exploit Schumpeterian opportunities.
\end{abstract}

\section{Introduction}

An entrepreneur is a person who recognizes an opportunity and acts to capture economic rewards derived from exploiting it. There are two types of entrepreneurial opportunities, one that is linked to Joseph Schumpeter's work (1942; tinyurl.com/7tzrbsk) and the other to Israel Kirzner's work (1973; tinyurl.com/6t87n3w).

John Sanguinetti launched two companies that had significant effects on the electronic design automation (EDA; tinyurl.com/bw5zf) industry. The innovation of the first company was a new technology, while the innovation of the second company was a new business model. Both opportunities will be shown to be of the Schumpeterian type.

This article first distinguishes a Schumpeterian from a Kirznerian opportunity and describes the EDA industry. Then, the two companies founded by John Sanguinetti are described. Three lessons learned from examining Sanguinetti's innovations are discussed. Finally, the article provides the conclusions. 


\section{Making Money from Exploiting Schumpeterian Opportunities}

Arthur Low

\section{Schumpterian Opportunities}

De Jong and Marsili (2011; tinyurl.com/cz5cxgn) distinguish between Schumpeterian and Kirznerian opportunities. A Schumpeterian opportunity disrupts the existing market. It offers to destroy the capital of incumbent firms. In contrast, a Kirznerian opportunity fills gaps in the existing system. It does not disrupt the capital of incumbent firms.

To illustrate the difference between Schumpeterian and Kirznerian opportunities, take the case of a rare snowstorm descending on a mountain pass. An entrepreneur arrives with their truck filled with snow tires to a strategic point on the mountain highway where they can sell tires at inflated prices to worried travelers. An "arbitrage" situation (i.e., taking advantage of a price difference between two or more markets) is a classic Kirznerian opportunity. The entrepreneur who exploits a Kirznerian opportunity capitalizes on their asymmetrical knowledge to fill a gap in the existing system. A Kirzernian opportunity is one where the market balance can be restored with a price adjustment. The entrepreneur who transports snow tires to a location where a much higher price can be negotiated does not destroy the capital invested in a tire store or tire manufacturing facilities. Thus, the way an entrepreneur profits when acting on a Schumpeterian opportunity is quite different from the way an entrepreneur profits when acting on a Kirznerian opportunity.

\section{The Verilog and VHDL Languages Used in In- tegrated Circuit Design}

Verilog (verilog.com) is a hardware description language (HDL; tinyurl.com/76tcfdo). Verilog was developed in the 1980 s as a proprietary language that engineers could use to describe hardware - specifically the digital logic functions of integrated circuits (ICs). By the end of the 1980s, Verilog had become the de facto industry standard for HDLs.

Also in the 1980s, another HDL known as VHDL (tinyurl .com/d8r55fd) was developed for the United States military and was donated to the Institute of Electrical and Electronics Engineers (IEEE; ieee.org). In 1987, VHDL became an IEEE standard. In 1989, Cadence Design Systems (cadence.com) acquired a simulator of logic designs coded in Verilog from Gateway Design Automation. For Cadence, this simulator was a strategic technology that effectively gave the company a monopoly in the IC design simulator market for at least five years. VHDL standardization efforts worked to close the functional lead that Verilog had over VHDL in the simulation of IC designs.

In response to the threat posed to its dominant market position by an open VHDL, Cadence decided to release the Verilog language as an open standard. In 1995, Verilog also became an IEEE standard.

\section{Sanguinetti's First Opportunity: A Verilog Compiled Simulator}

An entrepreneur will understand, often in a flash of insight, what a bit of "news" means in terms of an opportunity. The news that Verilog would be publicly released presented John Sanguinetti with an opportunity for which he was uniquely positioned to exploit. He realized that his deep knowledge of Verilog and experience in the industry could enable him to introduce a technology that could undermine the market value of Cadence's Verilog simulator.

Sanguinetti was a computer scientist at NeXT (tinyurl.com/8med8), a company Steve Jobs started after he left Apple. Sanguinetti had completed his PhD dissertation on compiler design and was also an experienced user of Verilog. Like all other Verilog "bigots", Sanguinetti did not accept the widely-held belief that VHDL would kill off Verilog. Many who were in the business of designing ICs participated in the technical debate on whether VHDL or Verilog was the better language. In November of 1991, Open Verilog International published the Verilog Language Reference Manual. Soon afterwards, Sanguinetti started working intensely on an innovation that would later be recognized as one of the key technologies that revived Veri$\log$ and assured its future.

Verilog is a programming language with a similar grammar and syntax to the $\mathrm{C}$ programming language, which is widely used by software developers. A software programmer using $\mathrm{C}$ would develop a program in humanreadable $\mathrm{C}$ then compile it into machine-readable code. Compiled programs run orders of magnitude faster than programs that are executed by a software interpreter, which interprets each chunk of code line-byline. The VerilogXL simulator that Cadence acquired from Gateway Design Automation was an interpreter. As IC designs became larger, the simulation run time using VerilogXL became excessively long. 


\section{Making Money from Exploiting Schumpeterian Opportunities}

Arthur Low

Sanguinetti developed a working prototype that could compile and simulate designs in Verilog in two months. He called it the Verilog Compiled Simulator, VCS. The VCS ran between 10 to 30 times faster than Cadence's VerilogXL interpreted simulator. At this time, NeXT was paying more than $\$ 100,000$ for one VerilogXL simulation license and so was every other company that needed to simulate gate-level netlists.

A compiled Verilog simulator offered an incredible customer value proposition relative to the existing solution. Sanguinetti had no need for outside investment. He recruited close friends with IC design and sales experience to join him in launching a new company to develop and market VCS. He then quit his job at NeXT.

Sanguinetti's new company was called Chronologic Simulation. No one drew a salary for the first 15 months of the company's operations. Within two months of releasing VCS, the startup had sold five licenses to NeXT (Sanguinetti's former employer), Sun Microsystems, and three other companies. Initial sales were mostly achieved through personal contacts in Silicon Valley. One week in 1992, the startup had approximately $\$ 1,000$ in a bank account; the next week, it had more than two million dollars in the same bank account. The startup had no external investors.

By 1994, Chronologic was on everyone's radar. Several companies, including Cadence, considered buying Chronologic. Since Cadence donated the Verilog language so that it could become an open standard, it may be that Cadence tolerated fair competition against its Cadence's VerilogXL simulator to further promote an open Verilog.

In early 1994, Sanguinetti and other Chronologic executives signed a letter of intent to merge with ViewLogic Systems, another provider of EDA tools. ViewLogic offered Chronologic stock worth $\$ 25$ million. Shortly after Chronologic signed the letter of intent, Synopsys, a larger EDA company, offered to purchase Chronologic for $\$ 25$ million in cash. According to the Chronologic team, ViewLogic had led them to believe they could stay in their own offices and keep operating as a separate division. Synopsys told them they would be absorbed. Moreover, had the Chronologic team accepted the Synopsys cash offer after signing the letter of intent with ViewLogic, the CEO of ViewLogic could sue each team member personally.
A year after the ViewLogic-Chronologic "merger", members of the Chronologic team felt aggrieved. Within a month of closing the deal, ViewLogic missed their numbers and the stock fell in response. ViewLogic controlled the Chronologic division and the other aspects of their EDA tool business were stagnant. Chronologic wanted changes, and brought their concerns to ViewLogic management. ViewLogic responded with a lawsuit. Most of the Chronologic staff quit within a week of the lawsuit. ViewLogic threatened Sanguinetti with legal action if he violated the non-compete clause in his contract. As a result, John Sanguinetti retired from the EDA business and pursued consulting work for several years.

\section{Sanguinetti's Second Opportunity: Release of CynLib C++ Library as Open Source}

John Sanguinetti's second startup made a strategic decision to release as open source an important EDA software technology: the innovative CynLib $\mathrm{C}++$ library. The CynLib library extended the popular $\mathrm{C}++$ software language to enable electronic system level (ESL) design. Thinking at the ESL level, logic designers model and verify their designs at a much higher level of abstraction than the logic described in Verilog. This advancement was important because the rapid growth in the size of IC designs required designers to describe more complex logic in shorter design cycles.

By 1998, new opportunities were emerging in the EDA industry and John Sanguinetti's non-compete clause had expired. He launched a new EDA company, CynApps, to develop an ESL design flow as a collection of software tools that together formed a complete end-toend "methodology" for IC design. Venture capital was needed to fund the intensive capital requirements of this new business. In the booming technology sector of the late 1990s, it was not possible to expect top-quality engineers to join a speculative project without being well paid for their efforts. After talking to a few venture capital firms, he raised the money to start CynApps.

A year after raising funds, CynApps technology was being licensed to companies at over $\$ 100,000$ per license. The core of the technology was the advanced $\mathrm{C}++$ library, CynLib.

Synopsys, one of the largest companies in the EDA industry, had developed a similar ESL technology called SystemC. Users and smaller EDA startups were worried 


\section{Making Money from Exploiting Schumpeterian Opportunities}

\section{Arthur Low}

that Synopsys would try to use its market power to ensure SystemC became an industry standard under its exclusive control. In 2001, Milton Lie, director of engineering of IC start-up Netrake, explained his concerns in an interview to EE Design (tinyurl.com/ch3hez5): "When I looked at these languages, I saw too many big companies with SystemC. My fear was that with so many big companies, with their own egos, it would be very hard to get off the ground. And I thought that Cynlib code, at that point, was a lot more mature."

CynApps, the startup, was not as powerful as Synopsys, the EDA giant. Sanguinetti informed Synopsys that he was considering releasing CynApps' CynLib C++ library as open source. By releasing CynLib as open source, the company hoped to stimulate engineers to adopt CynLib rapidly. Sanguinetti's observation of Linux and other open source projects led him to believe that many engineers would try CynLib and like it. He believed that CynLib users would be attracted to join the CynApps open source community and would work to preserve their experience. Some engineers might contribute to the code base for all sorts of reasons. In 1999, CynApps released CynLib as an open source $\mathrm{C}+++$ library. The CynApps product offer was much more than a library; it was an entire system-level design methodology. The release of the library as open source was not expected to adversely impact CynApps' revenue.

Synopsys had another strategy for SystemC. Synopsys released SystemC as a quasi-open language under a "community source" license as the foundation of the new Open SystemC Initiative. The EDA industry reacted negatively to the "Open" SystemC Initiative. Many were concerned that Synopsys might benefit unfairly from the contributions of other collaborators. Cadence, Mentor Graphics, and other EDA companies did not immediately join the Open SystemC Initiative. The failure of Synopsys to attract Mentor and Cadence to support SystemC threw the EDA industry into chaos.

Many feared the development of two new ESL standards. The industry remembered the Verilog vs. VHDL "language wars" of the previous decade. "We are bringing clarity to the chaos that prevails in the system-level design language world today and simultaneously opening up a whole new realm of opportunities," the Synopsys CEO, Aert de Geus said (tinyurl.com/bw59hmm). "The initiative is championing interoperability at the beginning of this market, and SystemC is the right solution," he continued. But in the same EDN article in September, 1999, John Sanguinetti disagreed: "They are taking a very different approach to 'openness' than we are, making it very explicit that they will control any modifications to the library," Chaos, in the example cited, was the word used by the man whose capital was about to be destroyed by the Schumpterian entrepreneur.

The situation with Synopsys and the Open SystemC Initiative came to a head in 2001. One of the three cochairs of the Open SystemC Initiative resigned and wrote a letter claiming that the open SystemC was a "Synopsys sham". The letter suggested that anti-trust laws might have been broken and SystemC's backroom deals might unfairly limit free-market competition. A law firm was asked to investigate the operation of the Open SystemC Initiative, and although the investigators reported no wrong-doing, Synopsys decided to release control of the organization it had started. This led to the release of SystemC as an open source C++ library, just like CynApps' CynLib.

The CynApps open source business model was an innovative concept in the EDA industry. The restrictive "community source" license for SystemC could not compete with CynApps' open source license for CynLib.

\section{Lessons Learned}

Three important lessons are learned from examining the effect that John Sanguinetti had on the EDA industry. First, deep knowledge and experience enable an entrepreneur to recognize and act on potential Schumpeterian opportunities. Dr. John Sanguinetti was a compiler design expert. His knowledge of Verilog and compilers as well as his experience in the EDA industry enabled him to recognize that the introduction of the Verilog Compiled Simulator, with an order of magnitude performance improvement over the existing Cadence VerilogXL system, could reshape his industry. He saw that his first company could make money by introducing a new technology that outperformed existing technology. Sanguinetti was very familiar with the effect that open source software had in the computer industry. His industry experience and knowledge about open source enabled him to recognize that his second company could make money by releasing the CynLib $\mathrm{C}++$ library as open source and selling a methodology plus a suite of tools. Both companies disrupted the existing market rather than filling gaps in the existing system.

The second important lesson is that exploitation of Schumpeterian opportunities requires combinations of 


\section{Making Money from Exploiting Schumpeterian Opportunities}

Arthur Low

technology assets and business models that significantly increase customer value. They are not just brought about by developing and introducing a novel technology. Schumpterian entrepreneurs bring chaos to the market as innovations create new opportunities. CynLib's release as open source destroyed Synopsys' business strategy to control modifications to SystemC. This required both technology and business model innovation. Synopsys planned to bring "clarity to chaos" by offering an "opportunity" via a community source license. However, CynApps rival technology combined with an open source license brought Synopsys' business conduct into conflict with its community, thus destroying its social capital.

The third lesson is that venture capital is not always required to exploit a Schumpeterian opportunity. For Sanguinetti's first company, an expert technologist working at home for a few months produced a technologically superior software innovation that delivered much higher value to customers than the available alternatives. The evidence was two million dollars in revenue from five initial customers in the first week of launch. Sanguinetti understood that loyal Verilog users would never change to VHDL unless there was no alternative. Sanguinetti's second company was financed with venture capital, providing the resources required to quickly bring to market a complex suite of software technology. More important, however, was the recognition that donating key IC design technology combined with a genuine commitment to support could enable an open community of users and contributors and create chaos in the EDA industry.

\section{Conclusion}

This article has highlighted making money from Schumpeterian opportunities rather than Kirznerian opportunities. John Sanguinetti's two companies, Chronologic Simulation and CynApps, are examples of an entrepreneur recognizing and acting upon opportunities that push an industry out of equilibrium. Sanguinetti's first company combined the publication of an open Verilog language standard with his compiler design expertise to introduce a faster Verilog simulator that undermined the value propositions and capital investments of the incumbent EDA companies. Sanguinetti's second company combined the technological innovation of an ESL design methodology with a novel business strategy of open source software and building a community of users and developers to destroy the social capital of a large EDA company that had tried to control the design libraries.
Three lessons were learned from this study of two Schumpterian opportunities introduced by the same man. First, deep knowledge and experience enable an entrepreneur to recognize and act on Schumpeterian opportunities. Second, exploitation of Schumpeterian opportunities requires combinations of technology assets and business models that significantly increase customer value; developing and introducing a novel technology is not enough. Third, venture capital may not be required. Aspiring entrepreneurs should pay close attention to the lessons learned from examining John Sanguinetti's two companies.

\section{Recommended Reading}

- John Sanguinetti's account of the start-up of Chronologic Simulation, the HDL wars, and the development of ESL technologies can be read in Chip Design Magazine: tinyurl.com/d7rv7yw

- John Cooley has for many years authored an industry blog called Deep Chip, which provides insider observations: deepchip.com

- The EE Times is a long-standing industry trade journal covering developments in the EDA industry: eetimes.com

\section{About the Author}

Arthur Low is the founder and Chief Executive Officer of Crack Semiconductor, a supplier of high-performance cryptographic silicon IP used in some of the most demanding security applications. Arthur has a number of patents in the field of hardware cryptography. He has worked for a number of IC startups as a Senior IC designer and Architect and gained much of his fundamental IC design experience with Bell-Northern Research in the early 1990s and with IBM Microelectronics in the late 1990s. Arthur has a BSc. degree in Electrical Engineering from the University of Alberta and is completing his MSc. degree in Technology Innovation Management in the Department of Systems and Computer Engineering at Carleton University.

Citation: Low, A. 2012. Making Money from Exploiting Schumpeterian Opportunities: John Sanguinetti and the Electronic Design Automation Industry. Technology Innovation Management Review. May 2012: 18-22. 